\title{
Genus Allium in CSBG Digital Herbarium
}

\author{
Nataliya Kovtonyuk $^{1 *}$, Irina Han $^{1}$, Evgeniya Gatilova ${ }^{1}$, and Nikolai Friesen ${ }^{2}$ \\ ${ }^{1}$ Central Siberian Botanic Garden SB RAS, Zolotodolinskaya str., 101, Novosibirsk, 630090, Russia \\ ${ }^{2}$ Botanical Garden of Osnabrueck University, Albrechtstrasse 29, Osnabrueck, 49078, Germany
}

\begin{abstract}
Two herbarium collections (NS and NSK) of the Central Siberian Botanical Garden SB RAS keep about 740,000 specimens of vascular plants, collected in Siberia, Russian Far East, Europe, Asia and North America. Genus Allium s. lat. Is presented by 6224 herbarium sheets, all of them were scanned using international standards: at a resolution of $600 \mathrm{dpi}$, the barcode for each specimen, 24-color scale and scale bar. Images and metadata are stored at the CSBG SB RAS Digital Herbarium, generated by ScanWizard Botany and MiVapp Botany software (Microtek, Taiwan). Datasets were published via IPT at the Global Biodiversity Information Facility portal (gbif.org). In total 207 species of the genus Allium are placed in the CSBS Digital Herbarium, which includes representatives from 13 subgenera and 49 sections of the genus. 35 type specimens of 18 species and subspecies of the genus Allium are hosted in CSBG Herbarium collections.
\end{abstract}

\section{Introduction}

For the taxonomic treatment it is necessary to study worldwide herbarium collections. The value and universality of herbarium specimens are recognized in most countries, where national and large regional herbariums are actively developing and improving [1, 2]. According to the data in Index Herbariorum as of 15 December 2019, there are 3324 active herbaria in the world, containing 392,353,689 specimens [3].

Historically at state moment, there are two herbarium collections at the Central Siberian Botanical Garden, Siberian Branch of the Russian Academy of Sciences (CSBG SB RAS): herbarium named after I.M. Krasnoborov (NS) and herbarium named after M.G. Popov (NSK). The first herbarium collection at the CSBG SB RAS was organized in 1946 on the base of herbarium sheets transferred from Medical and Biological Institute (Novosibirsk). The main additions to collection were made in 1970-1980 years by Siberian researchers, whose scientific works deal with territories of southern part of Krasnoyarskiy krai, Khakassia and Tuva. Tuva plants collection in CSBG SB RAS herbarium is the largest in the world and counts about 80,000 herbarium sheets. Since 1980 the collection was replenished by plants from West Siberia: Altai, Novosibirsk, Omsk and Kemerovo regions. Nowadays NS herbarium divided into divisions: Siberia, Tuva, Far East, European part of ex-USSR, Middle Asia, Caucasus, North America, Foreign Europe and Foreign Asia.

\footnotetext{
* Corresponding author: nkovtonyuk@.csbg.nsc.ru
} 
In 1978 Herbarium collection named after M.G. Popov with divisions of northern part of Krasnoyarskiy krai, West Siberia, Central Siberia, East Siberia, Europe, Asia and America was transferred from Irkutsk to CSBG SB RAS. NS and NSK collections contain about 800,000 herbarium specimens of vascular plants (740,000 specimens), mosses, lichens and fungi sampled in Siberia, Russian Far East, Europe, Asia and North America [4].

In 2017 a new research group USU-Herbarium was organized in CSBG with the purpose of digitization and management of herbarium specimens in the NS and NSK collections. The digitization was started from Primulaceae [5], Amaryllidaceae, Geraniaceae [6], Iridaceae for the project "Flora of Russia" and data was published as datasets at the Global Biodiversity Information Facility (gbif.org). The genus Allium L. is one of the largest genera in the family Amaryllidaceae. It comprises over 1000 species, and the number is still increasing. In the APG III classification system, Allium is placed in the family Amaryllidaceae, subfamily Allioideae (formerly the family Alliaceae). In some of the older classification systems, Allium was placed in Liliaceae. The new intergeneric classification system, based on molecular sequence data, subdivided the genus into 15 subgenera and more than seventy sections [7]. In more recent years nine further Allium sections were proposed [8].

The aim of this work is to present to the general public an extensive collection of one of the largest genera in the petaloid monocotyledons, stored in the Herbariums CSBG (NS and NSK).

\section{Materials and Methods}

All digitized herbarium specimens of genus Allium have been placed in the Digital herbarium CSBG SB RAS (http://herb.csbg.nsc.ru:8081) and most of them were examined by N. Friesen $[9,10]$. Digitization of herbarium specimens was initially undertaken for type specimens [11] with a customized HerbScan unit, which consisted of a flatbed scanner (Epson Expression 10000XL) modified for inverted use. Images and metadata for 22 Allium type specimens preserved at the NSK are currently available on the Virtual Herbaria web site at the University of Vienna, Austria (http://herbarium.univie.ac.at/database) and 12 of them in JSTOR (https://plants.jstor.org). A new research group USU-Herbarium was organized in the CSBG in the end of 2017 with the purpose of digitization and management of herbarium specimens in NS and NSK collections. Currently digitization of samples is carried out using two ObjectScan 1600 scanners. Each workstation consists of an ObjectScan 1600 scanner, ScanWizard_Botany software and MiVapp_Botany archive management system software (Microtek, Taiwan). This integrated workstation is characterized by on-top scan design for full-frame focus, a maximum of $1600 \mathrm{dpi}$ (equal to 1 Gigabyte pixels), color CCD, Optical Character Recognition (OCR) for specimen label and ID barcode, and image archive and privileged-account cloud management system. Specimens were scanned using international standards: with the resolution of $600 \mathrm{dpi}$, a barcode for each specimen, and a 24-color scale and scale bar. The CSBG Digital Herbarium taxonomic database is compatible with the international resource, Catalogue of Life (http://www.catalogueoflife.org), where an updated list of taxa is published every month [12]. Originally, only $12,8 \%$ of labels had collection point coordinates when digitizing samples. Irina Khan was specially engaged in search of coordinates using different resources on the Internet. These coordinates are entered in the Digital Herbarium by Evgeniya Gatilova. Now we have more than $85 \%$ of samples with coordinates and maps of areas can be viewed at gbif.org. 


\section{Results}

Label metadata analysis has yielded the following results. In total 6224 samples from 207 species of the genus Allium are placed in the CSBS Digital Herbarium [13, 14]. In the M.G. Popov Herbarium (NSK) there are 106 species of the genus Allium, including Allium neriniflorum (Herb.) G.Don. In Krasnoborov Herbarium (NS) 204 species of Allium are represented.

\subsection{Type specimens}

The typothecary stores 22 type specimens from NSK's herbarium of the genus Allium [15]. There are holotypes for two taxa: Allium rupestristepposum N. Friesen (NSK0000019) and $A$. montibaicalense N. Friesen (NSK0000015). There are isotypes for 19 taxa $A$. altyncolicum N. Friesen (NSK0000007), A. anisopodium Ledeb. (NSK0000027), $A$. burjaticum N. Friesen (NSK0000008, NSK0000009), A. chamarense M. M. Ivanova (NSK0000010 и NSK0000011), A. dauricum N. Friesen (NSK0000022), A. malyschevii N. Friesen (NSK0000023), A. montibaicalense N. Friesen (NSK0000016, NSK0000017, NSK0000018), A. rupestristepposum N. Friesen (NSK0000020, NSK0000021), $A$. vodopjanovae N. Friesen (NSK0000012, NSK0000013, NSK0000014, NSK0000024, NSK0000025, NSK0000026) and one isolectotype $A$. amblyophyllum Kar. et Kir. (NSK0000028).

In Herbaria NS there are 13 type specimens of the genus Allium: A. lutescens Vved. (NS0000087), A. dolichomischum Vved. (NS0000084), A. transvestiens Vved. (NS0000090), A. grumm-grshimailoi Kamelin et Namz. (NS0000085, NS0000086), A. senescens L. subsp. glaucum (Schrad.) Friesen (NS0000088, NS0000089), A. shevockii McNeal (NS0016169) and $A$. nevskianum Vved. ex Wendelbo (NS0015725), $A$. schischkinii Sobolevsk. (NS0014707, NS0014709, NS0014710, NS0014711).

\subsection{Historical analysis}

In Herbarium collection the earliest specimens are the collections of Karelin and Kirilov, for 1840-1841. There are 18 specimens from Kazakstan (Dzungaria and Dzungarian Alatau): Allium azureum Ledeb. (NSK0031212), A. amblyophyllum Kar. et Kir. (NSK0000028, isolectotype); A atrosanguineum Schrenk (NS0015736, NSK0031187), $A$. caeruleum Pall. (NS0015783), A. flavidum Ledeb. (NSK0031229), A. hymenorhizum Ledeb. (NS0015841, NS0015843), A. monadelphum Less. ex Kunth (NS0015858, NS0015859, NS0015860), A. pallasii Murray (NS0015877), A. platyspathum Schrenk (NS0015884, NS0015886), A. polyphyllum Kar. et Kir. (NSK0031203), A. robustum Kar. et Kir. (NS0015890), A. subtilissimum Ledeb. (NS0015947), A. tulipifolium Ledeb. (NSK0031217).

The total amount of specimen for the 19th century is 34 herbarium samples, including samples of Tauscher D.A.J., Freyn J., Dichtl S.J., Winter H., Krylov P.N., Haussknecht C., Michno P., Nelson A., Lipsky V., Blumberg M., Fedchenko B., Litvinov D., Nelson E., Koch E. and Palibin I.V. The latest specimens are of I.N. Pospelov 23.08.2013, Taimyr; S.V. Soloviev, A.M. Samdan 12.08.2013 Altai.

The collection of onion in the Herbarium CSBG was supplemented by 1200 collectors, the most active of which collected more than 200 specimens: N. Friesen (660 specimens), I. M. Krasnoborov (412), D. N. Shaulo (330), M. N. Lomonosova. (238), G.A. Peshkova (232), V.M. Hanminchun (223). 


\subsection{Geographic analysis}

Except Russia (5641 samples), 10 countries of the former USSR are presented: Kazakhstan - 151; Tajikistan - 42; Turkmenistan - 30; Uzbekistan - 20; Kyrgyzstan - 19; Ukraine - 16; Azerbaijan - 14; Georgia - 9; Belarus - 3; Armenia - 1 and 15 foreign countries: Mongolia 146; USA - 51; China - 15; Moldova - 11; Romania - 10; Hungary - 5, Germany - 5, Canada - 5, Austria -3, Bulgaria - 3, Japan - 2, Slovakia - 1, Turkey - 1, France - 1, Croatia - 1.

Russia is represented by 42 subjects of the Federation. The largest number of samples is represented by the Republic of Tyva (1504), the Republic of Altai (1144), the Republic of Buryatia (774), the Irkutsk region (442), Republic of Khakassia (396), Krasnoyarsk krai (326), Transbaikalia krai (288), Novosibirsk region (172), Altai krai (171), Republic of Sakha Yakutia (152), Kemerovo region (58). The geographical map of Allium occurrences for NS and NSK collections was placed in the dataset at gbif.org [13].

\subsection{Taxonomic review}

Since the Herbaria of CSBG are Siberian, more than $95 \%$ of all of the collections of the species of the genus Allium are from Siberia, which is confirmed the number of samples of the most common onions in the Herbaria CSBG [13]. However, the onions collection in Herbaria NS and NSK contains representatives from 13 of the 15 described subgenera and more than 200 species from 49 sections and 80 sections of new classification of the genus Allium [7, 8, 16]. Among them are: subgenus Allium (sections Allium, Avulsea, Brevidentia, Caerulea, Codonoprasum, Costulata, Eremoprasum, Minuta, Pallasia, Scorodon), subgenus Amerallium (sections Amerallium, Arctoprasum, Briseis, Caulorhizideum, Lophioprason, Narkissoprason), subgenus Anguinum (section Anguinum), subgenus Butomissa (sections Butomissa and Austromontana), subgenus Caloscordum (section Caloscordum), subgenus Cepa (sections Annuloprason, Cepa, Condensatum, Sacculiferum, Schoenoprasum), subgenus Melanocrommyum (sections Acanthoprason, Acmopetala, Decipientia, Kaloprason, Megaloprason, Miniprason, Popovia, Procerallium, Pseudoprasum, and Regeloprason), subgenus Microscordum (section Microscordum), subgenus Nectaroscordum (section Nectaroscordum), subgenus Polyprason (sections Daghestanica, Falcatifolia, Oreiprason and Scorodon), subgenus Porphyroprason (section Porphyroprason), subgenus Reticulatobulbosa (sections Campanulata, Reticulatobulbosa and Scabriscapa), subgenus Rhizirideum (sections Eduardia, Rhisomatosa, Rhizirideum and Tenuissima). The full list of Allium species and metrics are published in the dataset at gbif.org [13].

We would like to thank staff of USU-Herbarium research group: L. Lukmanova, S. Krasnikova, I. Deyun, I. Eremin for the technical support of our research work and Dr. Yu. Pshenichkina for the Russian names of taxa in the Digital herbarium CSBG SB RAS.

\section{References}

1. S.A. James, P.S. Soltis, L. Belbin, A.D. Chapman, G. Nelson, D.L. Paul, M. Collins, Appl. Plant Sci. 6, 1024 (2018)

2. N.K. Kovtonyuk, Rast. Mir Asian Russia 1 (2017)

3. B.M. Thiers, The World's Herbaria 2019: A Summary Report Based on Data from Index Herbariorum 3.0, 10 January 2020 (2020)

4. N. Kovtonyuk, I. Han, E. Gatilova, Skvortsovia 4, 3 (2018) 
5. N.K. Kovtonyuk, I.V. Han, E.A. Gatilova, Rast. Mir Asian Russia 4 (2018)

6. N. Kovtonyuk, I. Han, E. Gatilova, V. Troshkina, Family Geraniaceae in CSBG SB RAS herbarium collections (NS, NSK). Version 1.1. Central Siberian Botanical Garden SB RAS. (2020). Occurrence dataset https://doi.org/10.15468/sunx5n accessed via GBIF.org on 2020-02-03.

7. N. Friesen, S. Smirnov, T.Herden, B. Oyuntsetseg, A. Shmakov, H.Hurka, Allium species of section Rhizomatosa, early members of the Central Asian steppe vegetation, in Flora-Morphology Distribution Functional Ecology of Plants 263, 151536 (2020)

8. S. Smirnov, M. Skaptsov, A. Schmakov, R. Fritsch. N. Friesen, Phytotaxa 303, 2 (2017)

9. N. Kovtonyuk, V. Barkalov, N. Friesen, Turczaninowia 12, 3-4 (2009)

10. N. Kovtonyuk, V. Barkalov, N. Friesen, Family Alliaceae Borkh., in Synopsis of flora of Asiatic Russia: vascular plants (Novosibirsk, 2012)

11. N.K. Kovtonyuk, Rast. Mir Asian. Russia 3 (2015)

12. Y. Roskov, G. Ower, T. Orrell, D. Nicolson, N. Bailly, P. Kirk, T. Bourgoin, R. DeWalt, W. Decock, E. Nieukerken, J. Zarucchi, L. Penev, eds., Species 2000 \& ITIS Catalogue of Life, 25th March 2019, Digital resource at www.catalogueoflife.org/col/ Species 2000: Naturalis, Leiden, the Netherlands (2020)

13. N. Kovtonyuk, I. Han, E. Gatilova, N. Friesen, Genus Allium in CSBG SB RAS herbarium collections (NS, NSK). Version 1.4. Central Siberian Botanical Garden SB RAS. Occurrence dataset https://doi.org/10.15468/e4hv2e accessed via GBIF.org on 2020-06-10.

14. N. Kovtonyuk, I. Han, E. Gatilova, Digital Herbarium Collections of the Central Siberian Botanical Garden SB RAS, Novosibirsk, Russia, in Information Technologies in the Research of Biodiversity, Springer Proceedings in Earth and Environmental Sciences, Springer, Cham. (2019)

15. N. Kovtonyuk, I. Han, S. Ovchinnikova, O. Nikiforova, N. Vlasova, I. Shekhovtsova, V. Doron'kin, V. Troshkina, E. Pinzhenina, I. Belyaeva, I. Eremin, Typotheca of the higher vascular plants stored in M.G. Popov Herbarium (NSK) at the Central Siberian botanical garden SB RAS. Version 1.4. Central Siberian Botanical Garden SB RAS. Occurrence dataset: https://doi.org/10.15468/qdfdqq

16. T.A. Sinitsyna, Vavilovia 2 (2019) 